\title{
Evaluation of malignancy in ring enhancing brain lesions on CT by thallium-201 SPECT
}

\author{
K Källén, M Heiling, A-M Andersson, A Brun, S Holtås, E Ryding, I Rosén
}

Department of Neurology K Källén

Department of Clinical Neurophysiology A-M Andersson E Ryding

I Rosén

Department of Neuroradiology M Heiling

Department of Pathology, University Hospital, S-221 85 Lund, Sweden A Brun

Correspondence to: Dr Kristina Källén, Department of Clinical Neurophysiology, Unversity Hospital, 22185 Lund, Sweden. Tel: $+46-46-1733$ 80 Fax: +46 -46-14 6528

Received 27 April 1996 and in final revised form 23 April 1997

Accepted 28 April 1997

\begin{abstract}
Objective-To investigate patients with cystic enhancing lesions on CT and to determine whether thallium-201 $\left({ }^{201} \mathrm{~T} 1\right)$ SPECT adds to further preoperative information in differential diagnosis between gliomas and abscesses.

Methods-Twenty one patients with cystic ring enhancing CT findings were studied and uptake indices were compared with CT enhancement volumes, histopathology, and survival times.

Results-Fourteen high grade gliomas, three low grade gliomas, and four abscesses were found. Uptake was higher in the highly malignant glioma group (median thallium index $(T I)=2.1)$, than in the low grade glioma group (median $\mathrm{TI}=1.4$ ) or among the abscesses (median $\mathrm{TI}=1.6$ ). Overlapping indices were found between high and low malignant cystic gliomas as well as between either one of the glioma groups and the infectious lesions, and there were no significant differences between groups. There was a level at the value 2 , where $T I \geqslant 2$ correlated with tumour diagnosis. One low grade tumour had an extremely high index and a very high enhancement volume. Indices correlated significantly with CT enhancement volumes $(P=0.005)$. There was no significant correlation between $\mathrm{T} 1$ indices and patient survival times among the high grade gliomas. One patient with a highly malignant tumour but low T1 uptake $<2$, had a survival $>$ five years.

Conclusions-It is concluded that high ${ }^{201} \mathrm{~T} 1$ uptake in enhancing cystic lesions is an indicator of highly malignant glioma. However, the differentiation between the high malignant gliomas and abscesses or low malignant gliomas by ${ }^{201}$ TL SPECT is only partial with an overlap between these groups.
\end{abstract}

(F Neurol Neurosurg Psychiatry 1997;63:569-574)

Keywords: cystic brain lesions; computed tomography; glioma; abscesses; single photon emission computed tomography; thallium-201; survival time

Lesions identified on CT with ring enhancement are diagnosed either as malignant tumours or infectious abscesses. ${ }^{1}$ As they present with the same or similar CT characteristics differential diagnostic problems are a common clinical reality for the radiologist in several of these cases. ${ }^{2}$ Thallium-201 single photon emis- sion tomography $\left({ }^{201} \mathrm{Tl}\right.$ SPECT $)$ has been reported as a method that can help to distinguish between the two diagnoses and also as a reliable method for grading of tumour malignancy as there is a specific ${ }^{201} \mathrm{Tl}$ uptake in highly malignant gliomas. $^{3-16}$ A $\mathrm{Tl}$ uptake index $<2$ is in previous reports consistent with a glioma of low malignancy grade..$^{3-5}$ The aim of this study was to investigate cystic enhancing CT findings and evaluate if ${ }^{201} \mathrm{Tl}$ SPECT adds to further diagnostic precision.

\section{Methods}

PATIENTS

Over a three year interval, 67 patients with suspected malignant glioma as judged from CT underwent brain ${ }^{201} \mathrm{Tl}$ SPECT. In an earlier study all of these patients with histologically defined gliomas were analysed. The present study selectively included all those 21 patients with cystic lesions with ring enhancement on CT.

Patients' (10 female and 11 male) ages ranged from 11 to 74 years,. All included patients had their CT and SPECT examinations performed preoperatively. Within an interval of 35 days from SPECT and CT examinations all patients were operated on and the final histological diagnosis was determined. Two patients underwent diagnostic biopsy, 15 patients underwent tumour resection. In four patients an infectious abscess was suspected. The cystic cavity was extirpated or punctured in two patients; the infectious diagnosis was verified by positive leucocyte SPECT in the other two cases.

Malignant gliomas were originally classified according to the histological classification method of Kernohan et al. ${ }^{17}$ This system includes four grades of primary astrocytoma, oligodendroglioma, or mixed oligoastrocytoma (I, II, III, IV) but gliomas with heterogeneous growth and areas of varying malignancy grades are common, when the most malignant part decides the grading level. Tumours grade I and grade II are grouped together as low grade gliomas, tumours II-III, III, and IV are grouped together as high grade gliomas. With reference to the World Health Organisation (WHO) classification ${ }^{18}$ this means that high grade gliomas in this study comprise anaplastic astrocytomas, anaplastic oligodendrogliomas, and glioblastomas, the others being low grade gliomas.

The clinical course of the patients was followed up for a minimum of three years and a maximum of six years. All patients with 
highly malignant tumours, except for one who is alive, were followed up until their death.

TECHNIQUES

The ${ }^{201} \mathrm{Tl}$ SPECT measurements were made with a brain dedicated SPECT camera (Tomomatic 564). Each patient was given an intravenous injection of $75 \mathrm{MBq}{ }^{201} \mathrm{Tl}$ in isotonic sodium chloride. Children were given $1 \mathrm{MBq}^{201} \mathrm{Tl} / \mathrm{kg}$ body weight. The patients were positioned in the SPECT camera five minutes after $\mathrm{Tl}$ administration. The ${ }^{201} \mathrm{Tl}$ uptake was recorded in 10 transaxial contiguous $1 \mathrm{~cm}$ thick slices from $1 \mathrm{~cm}$ below the orbitomeatal line and superiorly. The intraslice resolution was about $1 \mathrm{~cm}$ (full width, half maximum). Images were acquired with a three turns per minute continuous rotation for five minutes. We used a $47-87 \mathrm{keV}$ energy window around the $70 \mathrm{keV}$ photo peak. The reconstruction was done in a $64 \times 64$ image matrix. The images were reconstructed with filter back projection and a linear attenuation correction in the axial plane. The attenuation coefficient used was $16 \%$.

Preoperative CT was used as an anatomical guide. The ${ }^{201} \mathrm{Tl}$ uptake was measured in the slice corresponding to the location of the cystic enhancing lesion identified on CT. Without knowledge of the histology of the lesion, a cross sectional profile was drawn through the part of the cystic lesion with the highest ${ }^{201} \mathrm{Tl}$ uptake. The average value of the three adjacent pixels with the highest Tl uptake was used. For each patient we determined a ${ }^{201} \mathrm{Tl}$ index of the uptake within the cystic lesion relative to the mean of three homologous pixels on the contralateral side ( $\mathrm{TI}=$ tumour uptake/contralateral uptake). In one patient, the lesion was in the midline and consequently the TI was 1.0 . In that case the tumour uptake was compared with the uptake in a low uptake region in the lateral part of one hemisphere.

All patients had a preoperative CT examination before and after administration of con-

Table 1 Patients'age and sex

\begin{tabular}{|c|c|c|c|c|c|c|c|c|c|c|}
\hline \multirow{2}{*}{$\begin{array}{l}\text { Patient } \\
\text { No }\end{array}$} & \multirow[b]{2}{*}{ Age } & \multirow[b]{2}{*}{$\operatorname{Sex}$} & \multirow{2}{*}{$\begin{array}{l}\text { Tumour } \\
\text { grade }\end{array}$} & \multirow[b]{2}{*}{ Lesion position } & \multirow{2}{*}{$\begin{array}{l}\text { Survival } \\
\text { (weeks) }\end{array}$} & \multirow{2}{*}{$\begin{array}{l}\text { Size } \\
(m l)\end{array}$} & \multirow{2}{*}{$\begin{array}{l}\text { Enh } \\
(m l)\end{array}$} & \multicolumn{2}{|c|}{ Histology } & \multirow[b]{2}{*}{ TI index } \\
\hline & & & & & & & & $R$ & $B$ & \\
\hline 1 & 62 & $\mathrm{~F}$ & $\mathrm{H}$ & Temp rt & 39 & 88 & 36 & + & & 2.6 \\
\hline 2 & 11 & $\mathrm{~F}$ & $\mathrm{H}$ & Pons & 8 & 11 & 4 & + & & $1.1^{\star}$ \\
\hline 3 & 74 & $M$ & $\mathrm{H}$ & Front-par lt & 3 & 16 & 7 & & + & 3.4 \\
\hline 4 & 41 & M & $\mathrm{H}$ & Front-par lt & Alive & 28 & 10 & + & & 1.6 \\
\hline 5 & 67 & $M$ & $\mathrm{H}$ & Temp rt & 7 & 39 & 20 & + & & 2.5 \\
\hline 6 & 44 & M & $\mathrm{H}$ & Temp lt & 51 & 49 & 14 & + & & 1.3 \\
\hline 7 & 64 & $M$ & $\mathrm{H}$ & Par-occ rt & 13 & 87 & 31 & + & & 1.4 \\
\hline 8 & 79 & $\mathrm{~F}$ & $\mathrm{H}$ & Par lt & 12 & 25 & 21 & & + & 1.7 \\
\hline 9 & 63 & $\mathrm{~F}$ & $\mathrm{H}$ & Temp-par-occ lt & 32 & 45 & 29 & + & & 1.4 \\
\hline 10 & 46 & $M$ & $\mathrm{H}$ & Temp-par rt & 30 & 99 & 42 & + & & 3.5 \\
\hline 11 & 58 & M & $\mathrm{H}$ & Par lt & 26 & 94 & 47 & + & & 3.4 \\
\hline 12 & 72 & $\mathrm{~F}$ & $\mathrm{H}$ & Par lt & 21 & 8 & 6 & + & & 3.6 \\
\hline 13 & 67 & $M$ & $\mathrm{H}$ & Front-par lt & 12 & 90 & 32 & + & & 4.2 \\
\hline 14 & 40 & M & $\mathrm{H}$ & Front lt & 102 & 30 & 4 & + & & 1.0 \\
\hline 15 & 26 & $M$ & $\mathrm{~L}$ & Temp rt & Alive & 87 & 3 & + & & 1.3 \\
\hline 16 & 22 & $\mathrm{~F}$ & $\mathrm{~L}$ & Front rt & Alive & 106 & 84 & + & & 6.2 \\
\hline 17 & 43 & $M$ & $\mathrm{~L}$ & Temp lt & Alive & 47 & 4 & + & & 1.4 \\
\hline 18 & 49 & $\mathrm{~F}$ & Abs & Occ rt & Alive & 19 & 12 & & & 1.6 \\
\hline 19 & 31 & $\mathrm{~F}$ & Abs & Front-par rt & Alive & 49 & 21 & + & & 1.5 \\
\hline 20 & 66 & $\mathrm{~F}$ & Abs & Front rt & Alive & 14 & 7 & & & 1.9 \\
\hline 21 & 49 & $\mathrm{~F}$ & Abs & Front rt & Alive & 21 & 4 & + & & 1.0 \\
\hline
\end{tabular}

* Patient with tumour located in the midline with a false too low TI (1.0). In this case TI was defined as the tumour uptake relative to the uptake in the lateral part of the hemisphere. For tumour grading $\mathrm{L}=$ low grade $\mathrm{H}=$ high grade; $\mathrm{Abs}=$ abscess. For lesion position $\mathrm{lt}=\mathrm{left} ; \mathrm{rt}=$ right $;$ temp $=$ temporal; front $=$ frontal; par $=$ parietal occ $=$ occipital. Enh $=$ enhancement. For histology $\mathrm{R}=$ resected tissue; $\mathrm{B}=$ biopsy specimen. trast. Different modern CT scanners were used. The time interval between the SPECT and CT examination never exceeded six weeks (median 13 days). The slices were parallel to the orbitomeatal line and the thickness varied between $4-10 \mathrm{~mm}$ in the posterior fossa and 8-10 $\mathrm{mm}$ supratentorially. Contrast enhancement was achieved by a bolus injection of 100 $\mathrm{ml}$ iohexol $(300 \mathrm{mg} / \mathrm{ml})$ or $1.5 \mathrm{ml} / \mathrm{kg}$ body weight in patients with a body weight $<60 \mathrm{~kg}$. Total volume of the mass and the volume of the tissue with blood-brain barrier damage was measured by the same neuroradiologist in every patient. The total volume measured consisted of the area with blood-brain barrier damage, including areas with necrosis or cysts. The presence of blood-brain barrier damage was determined by visual comparison of precontrast and postcontrast images.

To measure the volume of the cystic lesions and their enhancement, a $5 \times 10 \mathrm{~cm}$ grid was drawn on a disposed transparent $x$ ray film using a $\mathrm{cm}$ scale, indicated on the image. The grid was placed on the lesion and areas of enhancement in every slice of the mass lesion and the area of enhancement or lesion volume were measured. The total volume was then calculated by multiplying the area of each slice with the slice thickness, and the volumes on each slice with pathology were added together.

\section{STATISTICAL ANALYSIS}

The results are expressed as medians and ranges. The relation between ${ }^{201} \mathrm{Tl}$ indices and enhancement volumes of high or low grade gliomas or infectious lesions were analysed with an unpaired $t$ test. The non-parametric Mann-Whitney $U$ test was used.The level of significance was set at 0.05 . Associations between ${ }^{201} \mathrm{Tl}$ indices and enhancement volumes were assessed by the Spearman rank correlation test. The computer program StatView 4.0 was used in the analyses.

\section{Results}

Fourteen patients had histopathologically verified cystic high grade gliomas and three patients had cystic low grade gliomas. Four patients had intracerebral infectious lesions. Table 1 shows the characteristics of patients and lesions.

One patient, a 22 year old woman, had a tumour showing contradictory features of high and low malignancy (table 1 patient 16). She presented with a two month history of fatigue, change in mental state, and severe headache. Her initial CT was in September 1992 and it indicated high grade glioma as the probable diagnosis (fig 1). Because of spots of calcification in the middle of the tumour it was assumed to be a mixed oligodendroastrocytoma of high malignancy grade. The highly malignant character of the tumour was further confirmed by ${ }^{201}$ T1 SPECT examination (fig 1 ). An operation was performed 19 days after the initial CT. Tumour growth was well demarcated from normal brain tissue and the tumour seemed to be radically extirpated. Histopathol ogically the tumour had a mixed and varied appearance with small areas of an 

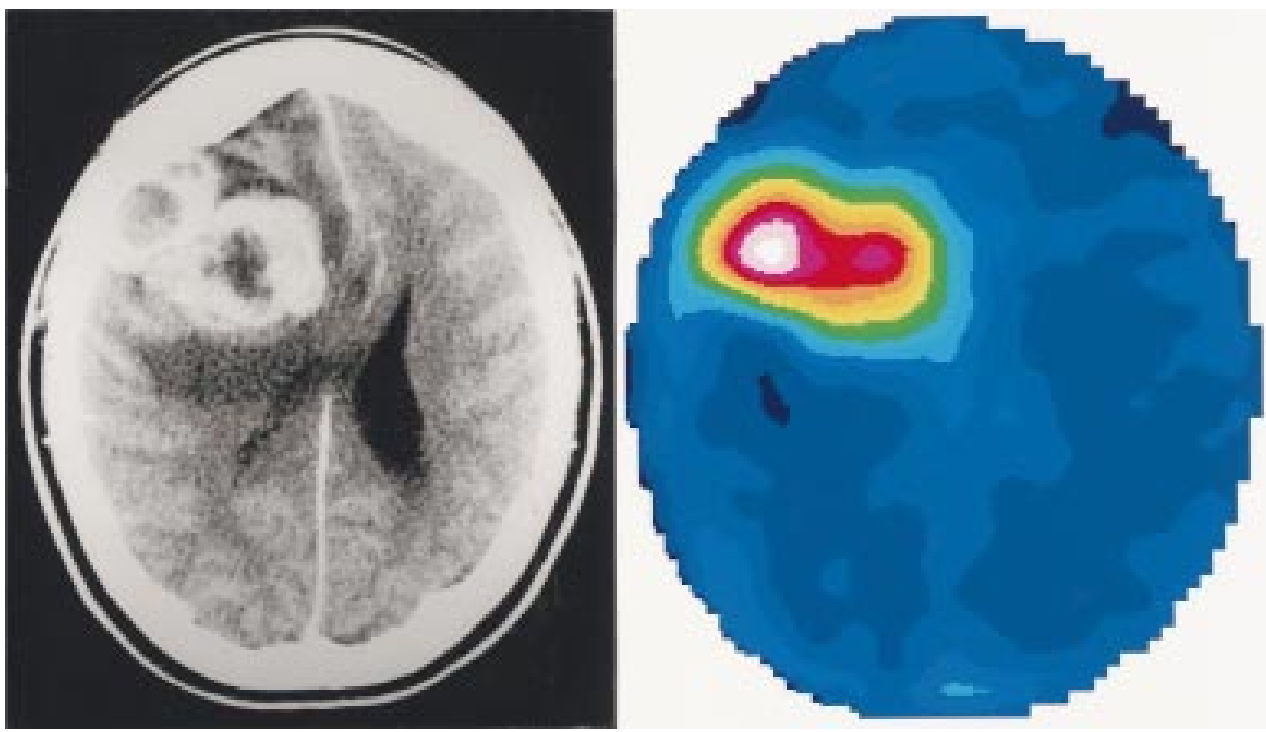

Figure 1 A rare low grade tumour with characteristics imitating high grade malignancy. The tumour was histologically defined as a pleomorfic xanthoastrocytoma but had an extremely high Tl uptake (TI 6.2) as well as a high enhancement volume $(84 \mathrm{ml}) . \mathrm{CT}$ and ${ }^{201} \mathrm{Tl}$ images. The colour scale shows white as highest and dark blue as lowest Tl uptake.

oligodendroglioma-like type including calcifications, but mainly a pleomorphic cell population with small to large cells with distinct cell membranes and irregular, sometimes multiple, nuclei and often a loose, granular cytoplasm. All of these cell varieties were positive to antibodies against glial fibrillar acidic protein. There were no necroses, only a rare vessel with a thickened wall, and a rare mitosis, features mitigating against a malignancy hinted at by the pleomorphic cell picture (fig 2). Against this background the process was diagnosed as a pleomorphic xanthoastrocytoma with a likely oligodendroglial component and of low grade malignancy. The patient did not receive any primary adjuvant therapy. Initially she had a benign postoperative course with no sign of clinical deterioration, then she developed epilepsy with rare partial complex seizures. During the spring of 1995 she experienced an increase in seizure frequency and a CT

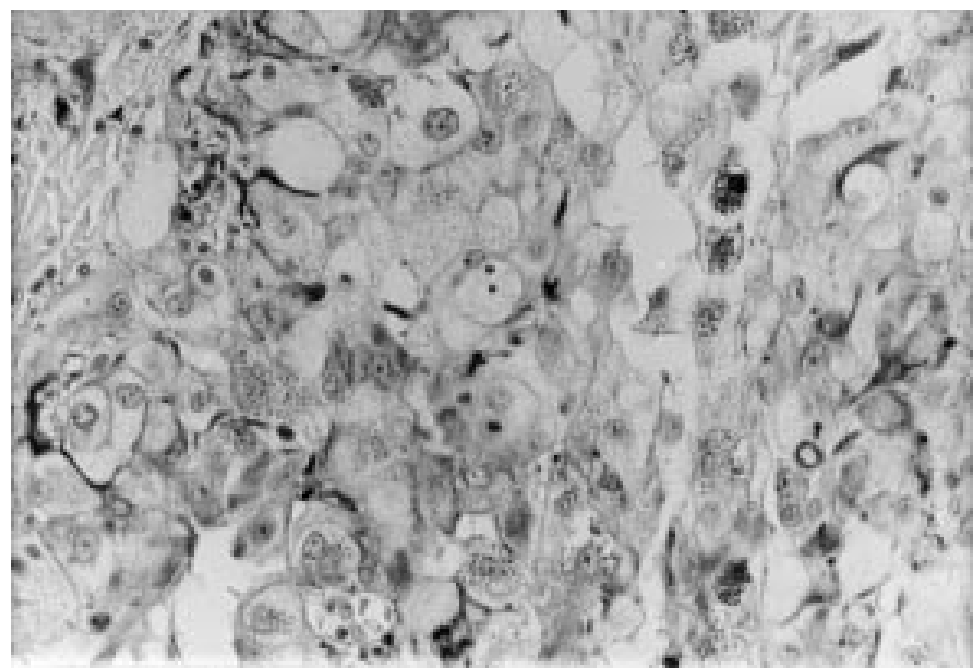

Figure 2 Microphotograph of pleomorphic xanthoastrocytoma, case 16, composed of large, rounded astrocytes with a distinct cell membrane and granular cytoplasm. Interspersed smaller cells and two larger and hyperchromatic nuclei render the picture moderately pleomorphic. Haematoxylin and eosin originally $\times 120$. examination disclosed a recurrent tumour located in the right frontal lobe-that is, in the same region as the original tumour was located. She was reoperated on in September 1995 with tumour resection and surgery was followed by radiation treatment. Her posttreatment CT has so far shown no signs of either residual tumour or tumour recurrence.

Indices of $\mathrm{Tl}$ uptake had a wide range in cystic high grade gliomas (table 2). One ring enhancing low grade glioma had an extremely high ${ }^{201} \mathrm{Tl}$ index. There was an overlap in ${ }^{201} \mathrm{Tl}$ indices between high grade and low grade gliomas and infectious lesions. There was no significant difference in ${ }^{201} \mathrm{Tl}$ uptake indices between high grade gliomas versus low grade gliomas or infectious lesions. There was an index level at the value 2.0 , where $T I \geqslant 2.0$ correlated with tumour diagnosis as all infectious lesions had a $\mathrm{TI}<2$. There was no clear level between high grade and low grade gliomas.

In a second analysis low grade gliomas and abscesses were put together as one group. The reason behind putting these two groups together was that both are suspected of having a low $\mathrm{Tl}$ uptake. Even in this case, no significant difference between groups was found.

In a third analysis the pleomorphic xanthoastrocytoma (patient 16) was considered an extreme outlier and was excluded from the group of low grade tumours. The tumour was atypical, and was measured and evaluated by different methods at separate times (fig $3 \mathrm{~A}$ and B). In this case neither the abscesses nor the low grade gliomas had any TI values exceeding 1.9. Again, when assessing the difference between the high grade gliomas versus the low grade and infectious lesions, no significant difference between groups was found.

Contrast enhancement volume on CT had a wide range in cystic high grade gliomas as well as in low grade gliomas. The pleomorphic xanthoastrocytoma had the highest contrast 
Table $2{ }^{201} \mathrm{Tl}$ indices and CT estimated enhancement volumes for cystic high grade gliomas, cystic low grade gliomas, and abscesses

\begin{tabular}{lcll}
\hline & High grade $(n=14)$ & Low grade $(n=3)$ & Abscess $(n=4)$ \\
\hline${ }^{201} \mathrm{Tl}$ index & $2.1(1.0-4.2)$ & $1.4(1.3-6.2)$ & $1.6(1.0-1.9)$ \\
CT enhancement volume (ml) & $20.5(4.0-47.0)$ & $4.0(3.0-84.0)$ & $9.5(4.0-21.0)$ \\
\hline
\end{tabular}

Values are median (range).

Table 3 Survival time for patients with cystic high grade gliomas

\begin{tabular}{llll}
\hline & $\begin{array}{l}\text { All high grade gliomas } \\
n=14\end{array}$ & $\begin{array}{l}\text { Low }{ }^{201} \text { Tl uptake } \\
n=7\end{array}$ & $\begin{array}{l}\text { High }{ }^{201} \text { Tl uptake } \\
n=7\end{array}$ \\
\hline Survival time (weeks) & $23.5(3.0-260.0)$ & $32.0(8.0-260.0)$ & $21.0(3.0-39.0)$ \\
\hline
\end{tabular}

Values are medians (range).

High uptake tumours, TI index $>2$; low uptake tumours, TI index $<2$.

enhancement volume (table 2 and fig $3 \mathrm{~B}$ ). Tested by the Mann-Whitney $U$ test enhancement volumes were significantly higher in high grade than in low grade gliomas only if the extreme outliner was excluded $(U=19.5$ tied $\mathrm{P}=0.038)$. There was an extensive overlap between enhancement volumes in high grade gliomas and infectious lesions and no demonstrable significant difference between the two groups. Among the high grade, low grade, and abscess lesions there was a highly significant correlation between ${ }^{201} \mathrm{Tl}$ indices and CT contrast enhancement volumes with the outlier included (tied $\mathrm{P}=0.005$ ) as well as without the outlier (tied $\mathrm{P}=0.012$ ).

Table 3 shows survival times. All patients with low grade tumours or abscesses were still alive at the end of the clinical follow up. Table 3 shows mean survival times among the group of patients with highly malignant gliomas. We evaluated the correlation between $\mathrm{TI}$ and survival time. Seven of the patients with highly malignant cystic tumours had low $\mathrm{Tl}$ uptake, defined as $\mathrm{TI}<2$, consistent with $\mathrm{TI}$ in low grade tumours in previous reports, ${ }^{3-5}$ or with the level between tumours and infectious lesions in this study. There was no significant correlation between $\mathrm{Tl}$ indices and survival times. Statistically, there was no evidence of less aggressive behaviour among the tumours graded as highly malignant but showing a low Tl uptake.
One of the patients with a cystic high grade glioma with low Tl uptake (patient 4, table 1) was alive at the end of the follow up time. His tumour was histologically classified as a glioblastoma multiforme, or according to the classification of Kernohan et $a l^{17}$ a glioma grade III-IV. The patient underwent whole brain irradiation to a dose of $58000 \mathrm{cGy}$ in the tumour bearing hemisphere and adjuvant combined chemotherapy consisting of procarbazine, vincristine, and lomustine (CCNU) in accordance with the local treatment regime. This case now has a follow up time of $>$ five years. His latest CT was in May 1996 and showed no sign of tumour recurrence.

\section{Discussion}

Thallium-201 SPECT has been proposed as a method for assessment of malignancy grade in gliomas. ${ }^{3-7}$ There is a selective uptake of ${ }^{201} \mathrm{Tl}$ in highly malignant glioma cells. The mechanism behind intracellular Tl uptake is probably an active transport by less selective ion channels in malignantly transformed glial cells. ${ }^{19-21}$ The cellular uptake is not solely related to cell biology in the tumour. The uptake is multifactorial, depending also on blood flow in the tumour, extent of pathological vessel invasion, and extent of blood-brain barrier breakdown.

In a recent study we evaluated the accuracy in preoperative glioma malignancy grading on the basis of ${ }^{201} \mathrm{Tl}$ uptake indices, CT findings, and histopathology. ${ }^{22}$ We found a significant correlation between CT enhancement volumes and ${ }^{201} \mathrm{Tl}$ uptake indices in high grade gliomas. Uptake of ${ }^{201} \mathrm{Tl}$ in non-enhancing gliomas was very low, independent of tumour malignancy grade. A disrupted blood-brain barrier seems to be a prerequisite for intracerebral penetration of $\mathrm{Tl}$ and its uptake in gliomas. This is expected as the $\mathrm{Tl}$ ion is polar and may only penetrate into the CNS when there is a disrupted blood-brain barrier. False negative scans were found as a result of shielding by the intact blood-brain barrier. Enhancement volumes correlated with ${ }^{201} \mathrm{Tl}$ uptake indices in this as well as in our previous report. The
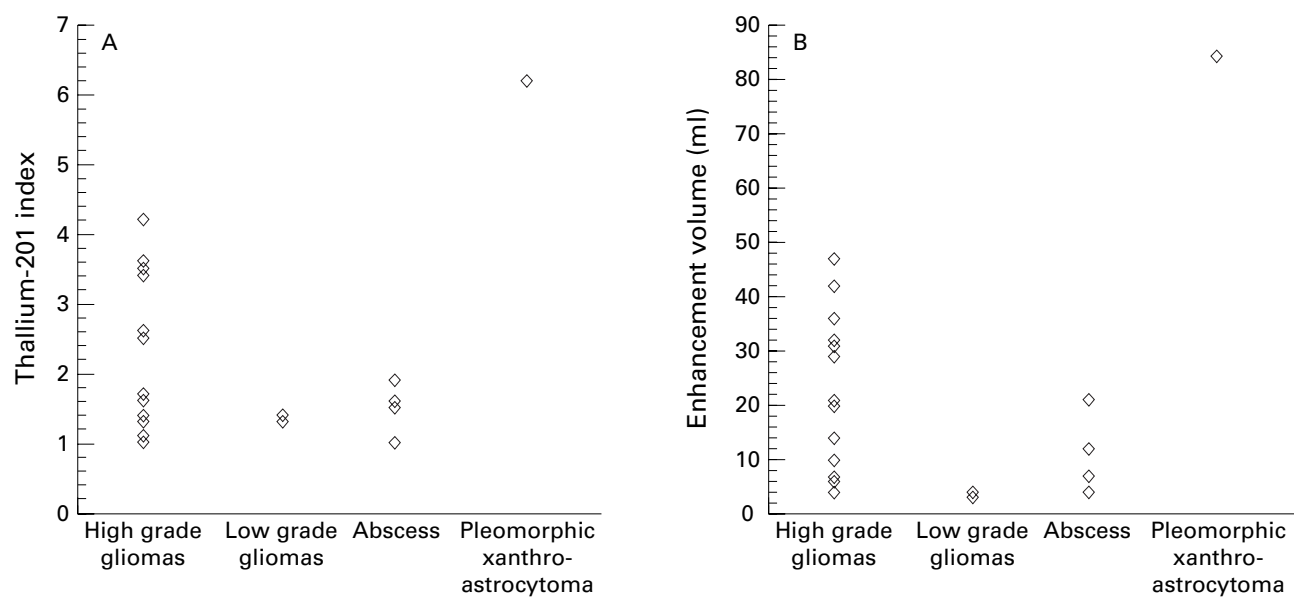

Figure 3 (A) Difference between ${ }^{201} T 7$ indices in histological groups, (B) difference between enhancement volumes in histological groups. The figure illustrates the extreme characteristics of the pleomorfic xanthoastrocytoma. High grade gliomas $n=14$; low grade gliomas $n=3$; abscesses $n=4$; pleomorphic xanthoastrocytoma $n=1$. 

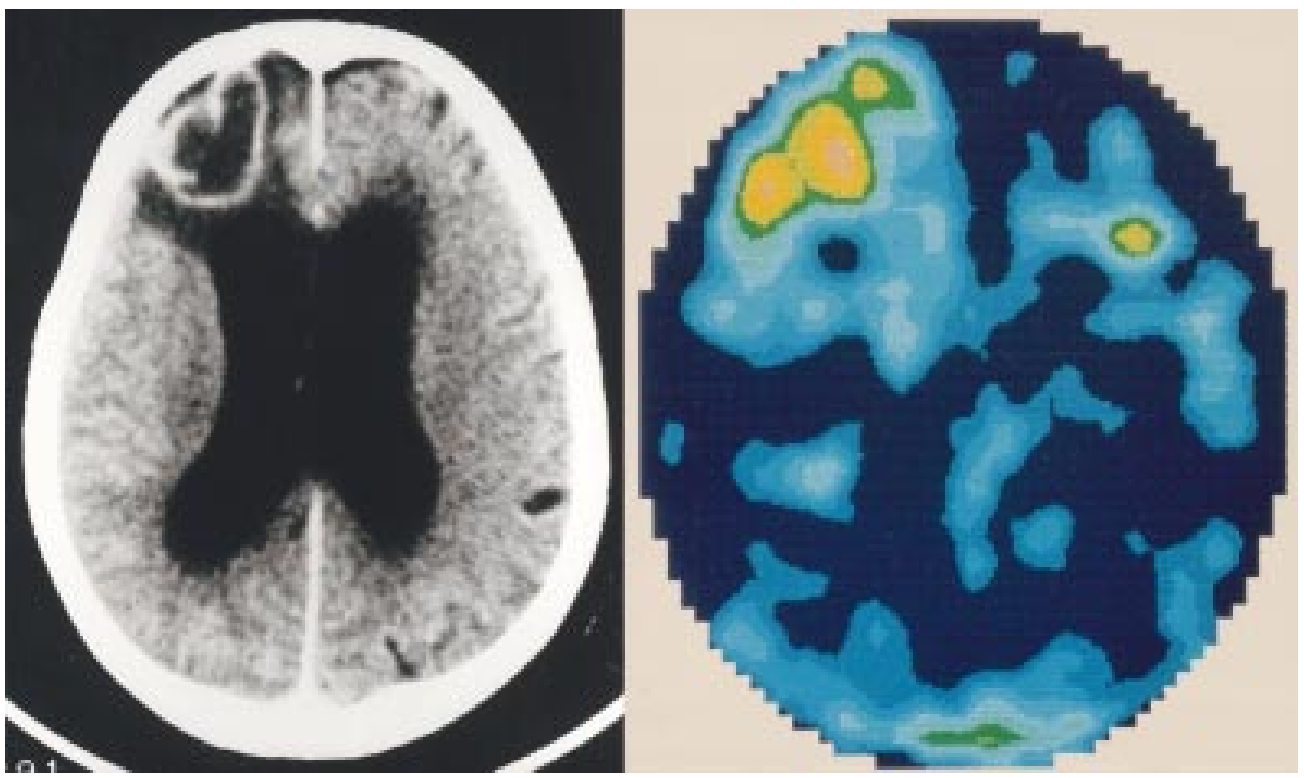

Figure 4 An abscess with moderately high Tl uptake (TI 1.9). CT and ${ }^{201}$ Tl SPECT images. The figure illustrates the need of caution when interpreting ${ }^{201}$ Tl SPECT images as some Tl accumulation was found in this infectious lesion.

importance of cell biology (malignancy grade) for $\mathrm{Tl}$ uptake seems to be of a more complicated nature than previously understood. The low grade malignant gliomas with small or moderate enhancement volumes had low ${ }^{201} \mathrm{Tl}$ uptake. The abscesses as a group seem to fall into the same category as the low grade gliomas.

In our previous report we found some cystic tumours of high malignancy grade to have low Tl uptake despite a disrupted blood-brain barrier. There is a risk for underestimation of tumour malignancy grade when using ${ }^{201} \mathrm{Tl}$ SPECT in cases of extensive presence of necrotic tumour areas in combination with moderate surrounding enhancement. Because cystic features on CT can be signs of a highly malignant glioma but also are characteristic of an infectious lesion-for example, a bacterial abscess, ${ }^{201} \mathrm{Tl}$ SPECT has been hypothesised to distinguish between the two diagnoses. In both cases there is a disrupted blood-brain barrier and a CT enhancement but factors facilitating a selective intracellular $\mathrm{Tl}$ uptake only exist when malignantly transformed cells are present. However, our results indicate that ${ }^{201} \mathrm{Tl}$ only allows a partial discrimination between cystic highly malignant gliomas and infectious lesions as partly overlapping ${ }^{201} \mathrm{Tl}$ indices exist between the two groups.

Ruiz et $a l^{23}$ suggested that ${ }^{201} \mathrm{Tl}$ SPECT was of value in discriminating lymphomas from infectious processes in patients with AIDS with intracranial mass lesions, as none of the patients with infectious lesions had a ${ }^{201} \mathrm{Tl}$ uptake. Other authors have reported ${ }^{201} \mathrm{Tl}$ uptake in infectious lesions. ${ }^{24-26}$ Abnormal intracerebral $\mathrm{Tl}$ localisation in a bacterial brain abscess was found by Krishna et al. ${ }^{26}$ Distribution of $\mathrm{Tl}$ in tumour tissue and inflammatory lesions has been studied in rats by Ando et al. ${ }^{27}$ Their results indicated that $\mathrm{Tl}$ accumulated mainly in tumour tissue but also to a lesser extent in subcutaneous inflammatory tissue specifically at sites where leucocytes and macrophages were crowded. ${ }^{27}$

In our material there is a case similar to that described by Krishna et al..$^{25}$ Patient 20 (table 1) had a moderately intense ${ }^{201} \mathrm{Tl}$ uptake in a cystic brain lesion that was found to be a bacterial abscess (fig 4). The TI is at the same level as that of a high grade glioma with a moderate enhancement volume. It must be stressed that many factors contribute to the intracerebral $\mathrm{Tl}$ uptake. Uptake of ${ }^{201} \mathrm{Tl}$ is an indicator of highly malignant tumour but $\mathrm{Tl}$ accumulation is also found to some extent in inflammatory or infectious tissue. In our material there is an index level at the value 2.0 , were $\mathrm{TI} \geqslant 2.0$ correlates with tumour diagnosis.

The case with a low grade tumour with high ${ }^{201} \mathrm{Tl}$ uptake and high enhancement volume is puzzling and shows that high ${ }^{201} \mathrm{Tl}$ uptake might also be found in occasional benign tumours of uncommon cell type and with blood-brain barrier damage. Findings from CT and $\mathrm{Tl}$ uptake in this case were both imitating the findings of a highly malignant glioma. The tumour showed contradictory features of a high and low malignancy character but was judged to be of low malignancy. This is in agreement with the WHO practice ${ }^{18}$ and the relatively benign postoperative course shown by the patient. In a previously published study early and late retention of Tl was measured. ${ }^{8}$ The authors found that early high and rapid uptake combined with slow reduction of $\mathrm{Tl}$ indicated a hypervascular malignant tumour. However, early high and rapid uptake but rapid reduction of $\mathrm{Tl}$ indicated a hypervascular benign tumour, such as a meningeoma. In this study we only evaluated early $\mathrm{Tl}$ retention and we do not know in what way the relatively benign pleomorphic xanthoastrocytoma would have reacted if late retention had been been measured. This single case confirms the need for caution when evaluating preoperative CT as well as ${ }^{201} \mathrm{Tl}$ SPECT. 
In the clinical follow up there was one case with a glioblastoma and an unexpectedly long survival. Even with aggressive therapy, the survival of adults with high grade astrocytomas is very limited. Virtually no one is cured from their illness. The median survival time is 18 months for patients with anaplastic astrocytomas and 12 months for patients with glioblastoma multiforme. ${ }^{28}$ However, there are other well known prognostic factors with significant impact on survival time such as age younger or older than 50 years and Karnofski performance greater or less than $70 .{ }^{29}{ }^{30}$ The median survival time of those with the best prognostic variables was 58 months in one published survival analysis of more than 1500 patients with high grade astrocytomas who entered clinical trials. ${ }^{30}$ A published meta-analysis for patients treated with both chemotherapy and radiation therapy found a median survival time of 12 months, with a range from seven to 46 months. ${ }^{31}$ Our patient with definite long term survival had a low $\mathrm{Tl}$ uptake despite a histologically defined glioblastoma multiforme. He was younger than 50 and had a Karnofski performance greater than 70 . Further studies are needed to elucidate if ${ }^{201} \mathrm{Tl}$ SPECT might be used as a prognostic tool in the few cases of relatively low $\mathrm{Tl}$ uptake in high grade gliomas.

We conclude that in cystic brain lesions ${ }^{201} \mathrm{Tl}$ SPECT allows a partial differentiation between high grade gliomas and low grade gliomas or infectious abscesses. Enhancing CT findings and high ${ }^{201} \mathrm{Tl}$ uptake in cystic lesions are both indicators of highly malignant gliomas but false negative as well as false positive findings exist with both methods. Diagnostic biopsy still seems necessary to establish a correct histological diagnosis in these cases. The study was supported by the Swedish Cancer Fund, grant No 0233-B94-03X,BB, and by the Swedish medical research Lindgren for statistical advice, and Professor LG Salford, Department of Neurosurgery, University Hospital of Lund, for continuous advice and support.

1 Butler AR, Horii SC, Kricheff II, Shannon MB, Budzilovich GN. Computed tomography in astrocytomas. Radiology GN. Computed

2 Choksey MS, Valintine A, Shawdon H, Freer CEL, Lindsay KW. Computed tomography in the diagnosis of malignan brain tumours: do all patients require biopsy? $f$ Neurol Neurosurg Psychiatry 1989;52:821-5.

3 Black KL, Hawkins RA, Kim KT, Becker DP, Lerner C, Marciano D. Use of thallium-201 SPECT to quantitate malignancy grade of gliomas. $\mathcal{F}$ Neurosurg 1989;71:342-6. 4 Kim KT, Black KL, Marciano D, Mazziotta JC, Guze BH, methods and results. 7 Nucl Med 1990;31:965-9.

5 Sjöholm H, Elmquist D, Rehncrona S, Rosén I, Salford LG. SPECT imaging of gliomas with thallium-201 and SPECT imaging of gliomas with thallium-201 and
technetium-99m-HMPAO. Acta Neurol Scand 1995;91:6670 .

6 Gruber ML, Hochberg FH. Editorial: systematic evaluation of primary brain tumors. $\mathcal{F}$ Nucl Med 1990;31:969-71.

7 Tonami N, Hisada K. Editorial: thallium-201 SPECT in evaluation of gliomas. F Nucl Med 1993;34:2089-90.

8 Ueda T, Kaji Y, Wakisaka S, Watanabe K, Hoshi H, Jinnouchi $\mathrm{S}$, et al. Time sequential single photon emission computed tomography studies in brain tumor using hallium-201. Eur f Nucl Med 1993;20:138-45.

9 Oriushi N, Tamura M, Shibazaki T, Ohye C, Watanabe N, Tateno $\mathrm{M}$, et al. Clinical evaluation of thallium-201 SPECT in supratentorial gliomas: relationship to histologic grade, prognosis and proliferative activities. $7 \mathrm{Nucl} \mathrm{Med}$ 1993;34:2085-9.

10 Yoshii Y, Sastou M, Yamamoto T, Yamada Y, Hyodo A, Nose T, et al. The role of thallium-201 single photon emission tomography in the investigation and characterisation of brain tumors in man and their response to treatment. Eur 7 Nucl Med 1993;20:39-45.

11 Carvalho PA, Schwartz RB, Alexander III E, Garada B, Zimmerman RE, Loeffler JS, et al. Detection of recurrent gliomas with quantitative thallium-201/technetium-99m HMPAO single-photon emission computerized tomography. $\mathcal{F}$ Neurosurg 1992;77:565-70.

12 Zhang JJ, Park CH, Kim SM, Ayyangar KM, Haghbin M. Dual isotope SPECT in the evaluation of recurrent brain tumor. Clin Nucl Med 1992;17:663-4.

13 Kaplan WD, Takvorian T, Morris JH, Rumbaugh CL, Connolly BT, Atkins HL. Thallium-201 brain tumor imaging: a comparative study with pathologic correlation. 7 Nucl Med 1987;28:47-52.

14 Schwartz RB, Carvalho PA, Alexander III E, Loeffler JS, Folksrth R, Holman BL. Radiation necrosis vs high-grade recurrent glioma: differentiation by using dual-isotope SPECT with thallium-201 and technetium-99m HMPAO. AfNR Am $\mathcal{F}$ Neuroradiol 1991;12:1187-92.

15 Slizofski WJ, Krishna L, Katsetos CD, Black P, Miyamoto C, Brown SJ, et al. Thallium imaging for brain tumors with results measured by a semiquantitative index and correlated with histopathology. Cancer 1994;74:3190-7.

16 Kimura H, Takeno Y, Fukushima T. Variation in appearance of glioma on serial thallium-201 SPECT; case report. Neurol Med Chir 1995;35:317-20.

17 Kernohan JW, Mabon RF, Svein HJ, Adson AW. A simplified classification of gliomas. Proceedings of the Staff Meetings of the Mayo Clinic 1949;24:71-5.

18 Kleihues P, Burger PC, Scheithauser BW. The new WHO classification of brain tumors. Brain Pathol 1993;3:255-68.

19 Brismar T, Collins P, Kesselberg M. Thallium-201 uptake relates to membrane potential and potassium permeability. Brain Res 1989;500:30-6.

20 Britten JS, Blank M. Thallium activation of the (Na-K-)activated ATP of rabbit kidney. Biochim Biophys Acta 1968; 159:160-6.

21 Sessler MJ, Geck P, Maul FD, Hor G, Munz DL. New aspects of cellular thallium uptake: $\mathrm{Tl}+-\mathrm{Na}-2 \mathrm{Cl}$ -cotransport is the central mechanism of ion uptake. $7 \mathrm{Nucl}$ Med 1986;25:24-27.

22 Källén $K$, Heiling $M$, Andesson AM, Holtås S, Brun A, Ryding E. Thallium-201 SPECT in preoperative glioma malignancy grading: a study comparing accuracy on the basis of T1-201 index, CT findings and histopathology. AfNR Am f Neuroradiol 1996;17:925-32.

23 Ruiz A, Ganz WI, Post MJ, Camp A, Landy H, Mallin W, Sfakianakis GN. Use of thallium-201 brain SPECT to differentiate cerebral lymphoma from toxoplasma encephalitis in AIDS patients. AfNR Am f Neuroradiol 1994;15:1885in $\mathrm{A}$.

24 Tonami H, Matsuda H, Ooba H, Yokoyama K, Hisada K, Ikeda K, et al. Thallium-201 accumulation in cerebral candidiasis. Clin Nucl Med 1990;15:397-400.

25 Aktolun C, Demirel D, Kir M, Bayhan H, Maden HA. Technetium-99m-MIBI and thallium-201 uptake in pulmonary actinomycosis. F Nucl Med 1991;32:1429-31.

26 Krishna L, Slizofski WJ, Katsetos CD, Nair S, Dadparvar S, Brown SJ, et al. Abnormal intracerebral thallium localization in a bacterial abscess. F Nucl Med 1992;33:2017-19.

27 Ando A, Ando I, Katayama M, Sanada S, Hiraki T, Mori H, et al. Biodistributions of Tl-201 in tumor bearing animals and inflammatory leisons induced animals. Eur $\mathcal{F}$ Nucl Med 1987;12:567-72.

28 Grossman SA, Norris LK. Adjuvant and neoadjuvant treatment for primary brain tumors in adults. Semin Oncol 1995;22:530-9

29 Sandberg-Wollheim M, Malmström P, Strömbladh L-G, Anderson $\mathrm{H}$, Borgström S, Brun A, et al. A randomized study of chemotherapy with procarbazine, vincristine, and omustine with and without radiation therapy for astrocytoma grades 3 and/or 4. Cancer 1991;68:22-9.

30 Curran WJ, Scott CB, Horton J, et al. Recursive partitioning analysis of prognostic factors in three radiation therapy oncology group malignant glioma trials. $\mathcal{F}$ Natl Cancer Inst 1993;85:704-10.

31 Fine HA, Dear KBG, Loeffler JS, Black PMcL, Canellos GP. Meta-analysis of radiation therapy with and without adjuvant chemotherapy for malignant gliomas in adults. Cancer 1993;71:2585-97. 